\title{
Optimization \\ of postpartum management in women with physiological childbirth
}

DOI 10.52739/bio-up.2.2021.16-21

Inna O. Doskoch', Daria A. Martynova', Shekhar Maan Shrestha², Ludwika Fortuna $^{2}$, Anatolii Ya. Senchuk ${ }^{1}$

\begin{abstract}
Aim of study was to reduce the frequency of inflammatory complications by optimizing therapeutic approaches during the postpartum period.
\end{abstract}

150 patients were examined after physiological delivery (main group) and divided into two study groups (I and II). The first group included 100 postpartum patients who took probiotics for 1 month, beginning 3-5 days after delivery. The second group consisted of 50 postpartum patients who were not prescribed probiotics. The control group included 50 patients of reproductive age.

The probiotic used in the experiment is the drug PROBEEZ® FEMINA. The materials used for the immunological study were washings of cervical mucus.

\section{RESULTS}

Analysis of the results of local immunity on the 3rd day of the postpartum period shows an increase in IgA (6 times), almost twofold increase in IgG, and a significant increase in IgM (16 times) compared with non-pregnant patients.

1.5-2 months after delivery, the group I women taking probiotics normalize the production of the secretory components by the cells of the genital tract.

In contrast to patients in group I, we observed smaller positive shifts in women in group II.

\footnotetext{
1 Department of Obstetrics and Gynecology, Private Higher Education Establishment Kyiv Medical University

2 Department of Pathological Anatomy, Histology and Forensic Medicine, Private Higher Education Establishment Kyiv Medical University
} 
Concentrations of all serum immunoglobulins (IgA and IgG) were higher in the samples obtained from the group II compared to the healthy non-pregnant women and that of patients of group I, who took probiotics in the postpartum period. The possible presence of an inflammatory process with a slow course in patients of group II was also indicated by high concentrations of IgM.

Prophylactic administration of probiotics in the postpartum period causes positive shifts in local immunity, which thereafter, 1.5-2 months period after delivery, are manifested by normalization of concentrations of immunoglobulins of classes secretory IgA, IgG, and IgM. The lack of prophylactic use of Lactoand bifidobacteria in the postpartum period is accompanied by local immune disorders, which is indicated by the presence of a slow subside of the inflammatory process and possible violations of the microbiota of the vagina, 1.5-2 months after delivery.

Keywords: postpartum period, physiological childbirth, local immunity, probiotic.

\section{INTRODUCTION}

The postpartum period is one of the most important periods of the women's life, during which all the changes caused by pregnancy are reorganized in the mother's body. Jian \& Min-jun (2015) There is an establishment of the function of the mammary glands, development of the feeling of motherhood, and the corresponding restructure of a woman's physiology, and psychology. Sridhar \& Salcedo (2017). However, the most significant changes occur in the reproductive system, Greenbaum, Greenbaum, Moran-Gilad, \& Weintraub (2019).

Due to a significant decrease in estrogen levels, and as a consequence, trauma to the vaginal canal and additional contamination with the intestinal microflora during childbirth, the microecology of the vagina undertakes significant changes Okoroh et al. (2018), Brunson, Klein, Olsen, Weir, \& Roberts. (2017), Goldthwaite, Sheeder, Hyer, Tocce, \& Teal (2017).

In the postpartum period, the number of nonspore-forming gram-negative anaerobes -
Bacteroides spp. and gram-negative facultative anaerobic bacteria - E. Coli significantly increases, while there is a drop in the levels of Lacto- and bifidobacteria Menard (2011), Goplerud, Ohm, \& Galask (1976), Gerson et al. (2020), Madaan et al. (2017).

It is proven that the physiological recovery of the microbiocenoses of the genitals occurs during the first weeks of the postpartum period. At this time, there are dynamic changes in the species and quantitative composition of the microflora, which can be manifested in different ways during the puerperium Sharma, (2016)., Hickman, Propst, Swenson, \& Lewicky-Gaupp (2020).

The scientific literature gives a clear position on the causes of infectious complications in the postpartum period, indicating that those are characterized by not only the presence of a bacterial or viral threat but also a decrease in the body's immune reactivity Provotorova \& Minaev (2015).

The most important for the immune function of the human body is the integrity and composition of bacterial flora of the intestinal mucosa since it contains $60 \%$ of the body's immune cells. For the opportunistic flora not to be able to create a source of infection, it is necessary to restore the integrity of the intestinal mucosa Ostapenko, Kvashenko, Akimova, \& Nosova (2017). When the intestinal function is restored - the immune function is also being regained, thus the synthesis of IgA by Peyer's patches is normalized which leads to an increase in the concentration of secretory IgA on the surface of the vaginal mucosa Sridhar \& Salcedo (2017), Akimoto-Gunther \& Svidzinsk (2016).

According to Martikainen (2009) taking eubiotic drugs, LACTOBACTERIN and BIFIDOBACTERIN, in the early postpartum period has a beneficial effect on the formation of normal microbiocenosis of the vagina. It does not only reduce the occurrence of enterobacteria, streptococci, and staphylococci, but also ensures the early replacement of these harmful species by symbiotic lactobacilli. The growing interest in probiotics is primarily due to the low effectiveness of standard therapies Kira (2017), Madaan et al. (2017). In the case of probiotic therapy, there is an increase in CD4 + and CD8 
+ T-lymphocytes, activation of macrophages by lactobacilli, stimulation of secretory immunoglobulin A and neutrophilic granulocytes, inhibition of the release of inflammatory cytokines, and increased activity of natural killer cells Akimoto-Gunther \& Svidzinsk (2016).

The WHO and the US Food and Drug Administration (FDA) and the Food and Agriculture Organization (FAO) classify probiotics as safe, with GRAS status (Generally Regarded As Safe). This means that they can be used without restrictions in the food and pharmaceutical industries Kovachev \& Dobrevski-Vacheva (2013).

Analysis of the scientific literature showed that the postpartum period is difficult and dangerous for women in terms of implementation and occurrence of purulent-septic processes. During this period there is a sharp drop in the efficiency of the human immune system caused by suppression of the body's defense systems (suppression of immune reactivity, decreased levels of Lacto and bifidobacteria, trauma to the vaginal canal and its contamination by intestinal microflora).

The aim of the study: To reduce the frequency of inflammatory complications by optimizing approaches to the postpartum period.

\section{MATERIALS AND METHODS OF RESEARCH}

Based on this goal, we examined 150 patients after physiological delivery (main group). All patients were examined on the 3rd day after delivery and 1.5-2 months after delivery. Depending on the approach to postpartum management, all women were divided into two subgroups. The first group (100 patients) included patients who took a probiotic in a dose of 1 tablet two times a day for 1 month, beginning the 3-5th day after delivery. The second group consisted of 50 patients after physiological childbirth who were not prescribed probiotics.

The control group included 50 patients of reproductive age who applied for a preventive gynecological examination.

As a probiotic in the experiment the drug PROBEEZ® FEMINA was selected, which contains Lacto- and bifidobacteria (Lactobacillus acidophilus $2.0 \times 10^{9} \mathrm{CFU}$, Lactobacillus rhamnosus $2.0 \times 10^{9} \mathrm{CFU}$, Lactobacillus casei $1.0 \times$ $10^{9} \mathrm{CFU}$, Lactobacillus reuteri $2.0 \times 10^{9} \mathrm{CFU}$, Lactobacillus plantarum $1.0 \times 10^{9} \mathrm{CFU}$, Lactobacillus fermentum $1.0 \times 10^{9} \mathrm{CFU}$, Bifidobacterium bifidum $1.0 \times 10^{9} \mathrm{CFU}$ and lactose)

Washings of cervical mucus were used as the materials for the immunological study

Determination of immunoglobulins IgA, IgM, IgG present in the cervical mucus washes was performed by enzyme-linked immunosorbent assay, using ELISA device from "Sunrise ${ }^{\mathrm{TM}} \mathrm{Te}-$ can" (Austria).

For the study, we used fresh material samples that were stored for up to 48 hours at a temperature of 2 to $12{ }^{\circ} \mathrm{C}$. To quantify secretory IgA (sIgA) in biological fluids, the method of solid-phase enzyme-linked immunosorbent assay, a set of "IgA secretory - ELISA - BEST" was performed.

\section{RESEARCH RESULTS AND DISCUSSION}

The age of the examined women ranged from 19 to 44 years. Average $27.9 \pm 6.1$ in subgroup I, $28.2 \pm 6.9$ in subgroup II and $28.4 \pm 67.2$ years in the control group.

We did not find a significant differences in the frequency of diseases of the urinary system and varicose between the different groups of examined patients.

Analysis of gynecological history data indicated the predominance of inflammatory diseases of the female genital organs, which is much higher compared to women in the control group and indicates a high infectious load: yeast colpitis ( $40 \%$ and $8 \%$ ), a history of chronic adnexitis (12\% and $4 \%$ ).

Bacterial vaginosis occurred in a history of $10 \%$ of patients in the main and $12 \%$ of the control group. A history of cervical pathology was present in every fourth patient (19\% and $18 \%$, respectively, in the main and control groups). Confirmation of the presence of moderate hormonal disorders in the examined patients is a violation of the menstrual cycle (8 \% and $4 \%$ ) and the presence of leiomyoma of the uterus $4 \%$, respectively. 
Among the features of pregnancy in the examined patients, the most common complications of pregnancy were colpitis in pregnant women, which was found in 45 (45\%) patients of the main group and among 21 (42\%) women of the control group $(p>0.05)$

The threat of abortion and the threat of premature birth in women of the main group accompanied pregnancy in $27(27 \%)$ cases and $11(22 \%)$ pregnant women of the control group $(p>0.05)$. Anemia in patients of the main group was observed in 29 (29\%) and 12 (24\%) of the control group. Premature rupture of membranes was observed in $11(11 \%)$ of the examined main group and 5 (10\%) pregnant women of the control group. Swelling, proteinuria, and mild preeclampsia complicated pregnancy in 11 $(11 \%)$ pregnant women in the main group and 5 patients $(10 \%)$ in the control group. Placental dysfunction was diagnosed in $7(7 \%)$ subjects of the main group, and in pregnant women of the control group these disorders were detected in $3(6 \%)$ cases. Gestational pyelonephritis was detected in $5(5 \%)$ pregnant women of the

\section{Table 1}

The concentration of immunoglobulins in cervical mucus collected within 3-4 days of the postpartum period (Main group) and in 1,5-2 months (I-st and II-nd groups) after childbirth (M) \pm m

\begin{tabular}{|c|c|c|c|c|}
\hline \multirow{2}{*}{$\begin{array}{c}\text { Class } \\
\text { Iglg }\end{array}$} & \multicolumn{4}{|c|}{ Groups of patients were studied } \\
\cline { 2 - 5 } & $\begin{array}{c}\text { Controlgroup } \\
\mathrm{n}=50\end{array}$ & $\begin{array}{c}\text { Main group } \\
\mathrm{n}=150\end{array}$ & $\begin{array}{c}\text { Subgroup I } \\
\mathrm{n}=100\end{array}$ & $\begin{array}{c}\text { Subgroup II } \\
\mathrm{n}=50\end{array}$ \\
\hline $\lg \mathrm{g} / \mathrm{I}$ & $0.451 \pm 0.02$ & $3.041 \pm 0.83 *$ & $0.656 \pm 0.14 \Delta$ & $1.157 \pm 0.18 \#$ \\
\hline $\operatorname{lgG} / \mathrm{I}$ & $2.774 \pm 0.11$ & $4.665 \pm 0.92 *$ & $2.875 \pm 0.09 \Delta$ & $3.709 \pm 0.32 \#$ \\
\hline $\operatorname{IgM~g~/~I~}$ & $0.067 \pm 0.01$ & $1.114 \pm 0.71 *$ & $0.112 \pm 0.03 \Delta$ & $0.532 \pm 0.07 \#$ \\
\hline slgA mg / L & $2.452 \pm 0.14$ & $0.267 \pm 0.08 *$ & $2.131 \pm 0.12 \Delta$ & $1.709 \pm 0.16 \#$ \\
\hline
\end{tabular}

Note:

$*$ - the discrepancy of the results is significant $(p<0.05)$ between the indicators of the control and main groups;

$* *$ - the discrepancy of the results is significant $(p<0.05)$ between the indicators of the control and I-st subgroup;

\# - the discrepancy of the results is significant $(\mathrm{p}<0.05)$ between the indicators control and II-nd subgroup;

$\Delta-$ the discrepancy of the results is significant $(\mathrm{p}<0.05)$ between the indicators of the I-st and II-nd subgroups. trol group. Bleeding was observed in 2 (2\%) patients of the main group and $1(2 \%)$ of the pregnancy were observed in $22(22 \%)$ cases in the main group, and in the control group - in 7 Analyzing the results of childbirth, it should be At parity: first-time pregnant women in the main group $41 \%$; in the control group, this or more births in the anamnesis for the main group - $40 \%$ and $19 \%$; in the control group Significant changes in local immunity on the 3 rd day of the postpartum period compared to healthy non-pregnant women is evidenced by a arge, more than 6-fold increase in IgA, almost the control to $4,665 \pm 0,92 \mathrm{~g} / \mathrm{l}, \mathrm{p}<0,05)$ and a 16-fold increase in $\operatorname{lgM}$ (respectively $0.067 \pm$ $0.01 \mathrm{~g} / \mathrm{I}$ and $1.114 \pm 0.71 \mathrm{~g} / \mathrm{l}$ ) (Table 1) main group and in 2 (4\%) women of the concontrol group. Combined complications during figure equaled $40 \%$. Respectively, two and 3 
These results indicate increased permeability of vascular walls for IgA and IgG circulating in the vascular bed, as well as increased exposure to IgM in response to microbial colonization of the vagina on the 3rd day of the postpartum period. Such reaction can be considered positive, adaptive-protective, which is aimed to prevent the penetration of pathogens into the uterus and obviate the inflammatory processes in the postpartum period. This reaction is especially important in the postpartum period when the secretion of the secretory components by the apical parts of the cylindrical epithelium of the cervical canal is significantly reduced, which leads to a large decrease in secretory IgA concentrations in cervical mucus $(0.267 \pm 0.08 \mathrm{mg} / \mathrm{l})$.

Within 1,5-2 months after childbirth, the women accepting probiotics in the postpartum period have their secretory components restored to standard levels by the cells of the cervical channel.

This is indicated by the normalization of secretory IgA levels $(2.131 \pm 0.12 \mathrm{mg} / \mathrm{l})$ in these patients, which does not differ $(p>0.05)$ that much from this indicator in the control $(2.452$ $\pm 0.14 \mathrm{mg} / \mathrm{l})$.

In contrast to patients in subgroup I, we observed smaller positive changes in women in subgroup II. Concentrations of all serum immunoglobulins (IgA and IgG) were significantly $(p<0.05)$ higher compared to the healthy non-pregnant females and subgroup I patients, which were given the probiotics in the postpartum period. This indicated lagging normalization of vascular wall permeability for immunoglobulins. The possible presence of an inflammatory process with a slow recovery is also indicated by high concentrations of IgM $(0.532 \pm 0.07 \mathrm{~g} / \mathrm{l})$, which significantly exceed the corresponding values in healthy women in the control group $(0.067 \pm 0.01 \mathrm{~g} / \mathrm{l})$ and patients of subgroup I $(0.112 \pm 0.03 \mathrm{~g} / \mathrm{l})$. There is also no normalization of secretory IgA production after 1,5-2 month period, and its concentrations are significantly $(p<0.05)$ lower $(1.709 \pm 0.16 \mathrm{mg} / \mathrm{l})$ compared with women in the control group $(2.452 \pm 0.14 \mathrm{mg} / \mathrm{l})$ and patients who took probiotics $(2.131 \pm 0.12 \mathrm{mg} / \mathrm{l})$.

Thus, this research concludes prophylactic administration of probiotics in the postpartum period causes positive shifts in local immunity, which are proven by the fact that after regular intake of probiotics, 1.5-2 months after delivery, there is the normalization of concentrations of immunoglobulins of classes $A$, $G, M$, and secretory IgA. The absence of prophylactic oral use of Lacto- and bifidobacteria in the postpartum period is accompanied by local immune disorders, which is indicated by the presence of such females having slowly recovering inflammatory process caused by childbirth and possible violations of the microecology of the vagina 1.5-2 months after birth as we have seen in our research

The patients we examined underwent a full course of probiotics. None of the patients reported side effects.

\section{CONCLUSIONS}

On the 3rd day of the postpartum period there are significant changes in local immunity: compromised defense systems of the female body expose them to a high risk of inflammatory complications.

Prophylactic use of probiotics leads to normalization of sIgA levels (in patients who did not take probiotics $1.5-2$ months after delivery, there was a violation of local immunity still present).

The obtained results allow to recommend oral administration of probiotics for the prevention of infectious complications in the postpartum period.

\section{REFERENCES}

Jian, S., \& Min-jun SU (2015). Features of vaginal bacteria community in women with recurrent vulvovaginal candidiasis. Journal of Reproduction and Contraception, 26(4), 229-238.

Ostapenko. O.I., Kvashenko V.P., Akimova I.K., \& Nosova I.M. (2017). The effect of probiotics on the level of immunoglobulin $A$ in women with impaired vaginal biocenosis. Women's Health, (1), 85-88. 
Sridhar, A., \& Salcedo, J. (2017). Optimizing maternal and neonatal outcomes with postpartum contraception: impact on breastfeeding and birth spacing. Maternal health, neonatology and perinatology, 3(1), 1-10.

Menard, J. P. (2011). Antibacterial treatment of bacterial vaginosis: current and emerging therapies. International journal of women's health, 3, 295.

Goplerud, C. P., Ohm, M. J., \& Galask, R. P. (1976). Aerobic and anaerobic flora of the cervix during pregnancy and the puerperium. American journal of obstetrics and gynecology, 126(7), 858-868.

Kira, E. F. (2017). Probiotics in the restoration of vaginal microbiocenosis. Akusherstvo i Ginekologiya/Obstetrics and Gynecology, 5, 32-8.

Sharma, A. (Ed.). (2016). A practical guide to third trimester of pregnancy \& puerperium. JP Medical Ltd.

Provotorova, T. V., \& Minaev, N. N. (2015). Probiotics application prospects in the treatment of vaginosis: long-term effects. Eastern European Scientific Journal, (3).

Akimoto-Gunther, L., Bonfim-Mendonca, P. D. S., Takahachi, G., Irie, M. M. T., Miyamoto, S., Consolaro, M. E. L., \& Svidzinsk, T. I. E. (2016). Highlights regarding host predisposing factors to recurrent vulvovaginal candidiasis: chronic stress and reduced antioxidant capacity. PLoS One, 11(7), e0158870.

Gerson, K. D., McCarthy, C., Elovitz, M. A., Ravel, J., Sammel, M. D., \& Burris, H. H. (2020). Cervicovaginal microbial communities deficient in Lactobacillus species are associated with second trimester short cervix. American journal of obstetrics and gynecology, 222(5), 491-e1.

Greenbaum, S., Greenbaum, G., Moran-Gilad, J., \& Weintraub, A. Y. (2019). Ecological dynamics of the vaginal microbiome in relation to health and disease. American Journal of Obstetrics and Gynecology, 220(4), 324-335.

Kovachev, S., \& Dobrevski-Vacheva, R. (2013). Probiotic monotherapy of bacterial vaginosis: a open, randomized trial. Akusherstvo i ginekologiia, 52, 36-42.

Madaan, A., Nadeau-Vallée, M., Rivera, J. C., Obari, D., Hou, X., Sierra, E. M., ... \& Chemtob, S. (2017). Lactate produced during labor modulates uterine inflammation via GPR81 (HCA1). American journal of obstetrics and gynecology, 216(1), 60-e1.

Okoroh, E. M., Kane, D. J., Gee, R. E., Kieltyka, L., Frederiksen, B. N., Baca, K. M., ... \& Barfield, W. D. (2018). Policy change is not enough: engaging provider champions on immediate postpartum contraception. American journal of obstetrics and gynecology, 218(6), 590-e1.

Brunson, M. R., Klein, D. A., Olsen, C. H., Weir, L. F., \& Roberts, T. A. (2017). Postpartum contraception: initiation and effectiveness in a large universal healthcare system. American journal of obstetrics and gynecology, 217(1), $55-\mathrm{e} 1$.

Goldthwaite, L. M., Sheeder, J., Hyer, J., Tocce, K., \& Teal, S. B. (2017). Postplacental intrauterine device expulsion by 12 weeks: a prospective cohort study. American journal of obstetrics and gynecology, 217(6), 674-e1.

Hickman, L. C., Propst, K., Swenson, C. W., \& Lewicky-Gaupp, C. (2020). Subspecialty care for peripartum pelvic floor disorders. American journal of obstetrics and gynecology, 223(5), 709-714.

\section{Corresponding author:}

Anatolii Ya. Senchuk, 0509453723@ukr.net

Manuscript was recieved on 28 August; accepted for publication on 25 October. 